endocrine hypothesis. For example, there must be in the population many men who have regularly donated blood every six months for many years. Obviously this is not equivalent to a monthly menstrual bleed. Nevertheless it would be interesting to see whether these men are in any way protected against coronary thrombosis as compared with a group of non-donors.

(2) If true the concept would mean that protection against coronary thrombosis could be provided at very low cost. There would be no need for life-long drug taking or dietary changes.

(3) If the bleeding hypothesis were true, the blood transfusion service would cease to have any problem in acquiring blood.

I realize that my hypothesis is very unlikely to be valid. But when so little progress is being made in other directions and when the potential rewards are so great, a survey of the effects of blood donation on coronary disease would appear to be worthwhile.-I am, etc.,

NAFISA HORROBIN.

Department of Medical Physiology,

University College,

\section{Hypokalaemia in Influenza}

SIR,-I was interested to read the comments by Drs. J. Stevenson, B. K. Mandal and M. H. Hambling (14 February, p. 429) on their experiences in the recent influenza epidemic. I note that one quarter of their cases in which the plasma potassium was estimated in 1969-70 showed a figure below $3.6 \mathrm{mEq} . / 1$.

My cases have not yet had their diagnosis proved virologically or serologically, but out of 37 presumed cases of influenza there were twelve deaths. In 26 the plasma potassium was estimated; in 15 (four fatal) this was less than $3.6 \mathrm{mEq}$./1. A few of these cases had received thiazide drugs, but in the case with the most persistently low levels, who was a previously healthy 32 year-old female, 28 weeks pregnant (the baby was later stillborn), no thiazide drugs had been used.

It is clear that the "epidemic" varied in its intensity and severity in different parts of the country. Some nearby villages were entirely unaffected. It is clear, also, that should a viral toxin produce tubular damage to account for failure of potassium conservation by the kidney, and hence hypokalaemia, this may take a few days to show itself, so that plasma potassium levels may not fall until three to four days after admission. Dr. F. O. MacCallum has been kind to point out that there is no viraemia in influenza, and any tubular damage must be due to a toxin.

We hope to learn from the examination of some of our necropsy material whether this hypothesis is correct.-I am, etc.,

\section{General Hospital, Kettering,}

G. S. Crockett.

\section{Kerslake Curette}

SIR,-The letter from Mr. J. M. McGarry (3 January, p. 49) gives me some concern because it may well suggest to the unknowing that the equipment which I devised with the help of Peacocks (Surgical \& Medical Equipment) Ltd. is inadequate.

I would like to say that many hundreds of these curettes have been sent all over the country and abroad and this is the first grumble regarding the "hemispherical type" curette which has come to my notice. Up to date, the only adverse criticism has, I am sure, been based on experience gathered from inadequately sterilized and overheated curettes. By this, I mean that the main virtue of the plastic suction curette is that the contents can be seen at the earliest opportunity. If the curette becomes opaque, this advantage is lost but the disadvantage Mr. McGarry mentions is, in fact, no worse than anyone carrying out termination of an early pregnancy by the traditional method of "snatch and grab." In other words, he has to make sure that the uterus is emptied of all solid material.

This being so, all that obviously is needed, even if Mr. McGarry's unfortunate experience is repeated, is that whoever is doing this operation should be fully aware of what is in the uterus before it is evacuated. This Mr. McGarry did not seem to have undue difficulty in ascertaining.-I am, etc.,

\section{Dorothea Kerslake.}

Newcastle upon Tyne.

\section{Modes of Memory}

SIR,- - It was of considerable interest to find Professor J. Z. Young (14 March, p. 647) quoting Piaget for the basic assumptions on which to base his own idea. Piaget's "clinical" technique has been criticized for relying on the interpretation of verbal responses of children. For an information theorist such as Young, such a method is inexact since it assumes "that the statistics of languages are constant. This is, at best, an approximation and for the study of behaviour in general would often be untrue-always untrue for an animal that is learning or forgetting."1

There is perhaps justification for both methods if their results are parallel. I have recently been struck by another example of parallel thinking - that between Young's neurological theory and Kelly's psychology of personal constructs. Young suggests an internal unified structure which is a model of the environment, built up by the continuous assimilation of perceptual events. This internal structure or model is also a structure of alternative possibilities of action; it is both model and plan. Kelly also postulates the development of an internal representation of the environment by means of tested alternative constructions which are used to predict and control events. ${ }^{2}$

Thus Young and Kelly both suggest an internal representation of the environment made up of a hierarchy of dichotomous choices (constructs) which are seen in terms of alternative possibilities of action in the environment. It is very surprising that these two writers should develop such similar models of behaviour when their possibilities of action (for example, methods of investigation) are so different.

The approximation of two theories in this way is productive of new hypotheses. For instance anxiety, according to Kelly, is the awareness that the events one is confronted with lie mostly outside the range of convenience of one's construct system. We can postulate that the frontal lobe is involved in controlling the events which will be assimilated into the construct system as new constructs. The prefrontal cortex is thought to inhibit the control system which inhibits afferent perceptual input, ${ }^{3}$ and loss of this part of the cortex will reduce and disorganize perceptual input. In fact prefrontal leucotomy impairs some aspects of registration and short term memory; it also reduces chronic anxiety. Thus it may impair the assimiliation of new constructs and promote the use of the existing construct system.

Behavioural training in the use of the existing construct system to construe new events effectively may be as useful in the treatment of chronically anxious patients as leucotomy. Possibly it may be achieved with the "Wisconsin General Testing" apparatus," or with the methods used by Bruner et al. ${ }^{5}$ on concept-formation. Such training would require a more sophisticated theory than the stimulus-response model which underlies present behaviour therapy methods. A psychoneurological theory does suggest possibilities for treatment involving higher layers of the construct sytem. Thought disorder and hallucinations may eventually be interpreted in terms of a possible treatment programme by the use of a theoretical structure unifying perceptual model and plan of action.-I am, etc.,

\section{R. D. HiNSHELWOOD.}

Marlborough Day Hospital,
London N.W.8.

REFERENCES

Young, J. Z., A Model of the Brain, London, Oxford University Press, 1964.

Bannister, D., in New Horizons in Psychology, ed. 1966

Pribram, K. H., in Proceedings of the 18th International Congress of Psychology, edited by T. Kussmann, P. Göttingen, Verlag für Psychologie, 1966
Poffen

Poffen, R. L., Pribram, K. H., and Robinson, R. S., Experimental Neurology, $1965,11,217$. B Study of Thinking, London, Chapman and
Hall, 1956.

\section{Unusual Effect of Fenfluramine}

SIR,-I wish to draw attention to possible side-reactions of the drug fenfluramine (Ponderax).

Recently I saw a 38-year-old married woman with no previous psychiatric referrals. She had a stable previous personality and her social situation was satisfactory. Because of increasing weight she was prescribed fenfluramine $20 \mathrm{mg}$. t.d.s. After three weeks on the drug her husband and friends remarked that she was depressed and slowed down. She was aware of being low in spirits, attributed this to the drug and stopped it. Her mood then improved and after an interval of several weeks she decided to restart fenfluramine because her weight was again increasing. Five days after restarting she set out on her weekly shopping expedition to the local supermarket. She was again feeling low in spirits and unusually agitated. In the supermarket she began to place goods in the wire carrier, but became increasingly confused, unable to find her purse, and feeling that she was late and must rush home. She then developed a state of depersonalization in which she was 